\title{
Traumatic brain injury, posttraumatic stress disorder, and pain diagnoses in OIF/OEF/OND Veterans
}

\author{
David X. Cifu, MD $;^{1-3^{*}}$ Brent C. Taylor, PhD $;{ }^{4-5}$ William F. Carne, PhD $;{ }^{2-3,6}$ Douglas Bidelspach, MPT; ${ }^{1,7}$ Nina A. \\ Sayer, PhD; ${ }^{4-5,8}$ Joel Scholten, MD; ${ }^{1,9}$ Emily Hagel Campbell, $\mathrm{MS}^{4}$ \\ ${ }^{1}$ Physical Medicine and Rehabilitation Program Office, Department of Veterans Affairs (VA), Washington, DC; \\ ${ }^{2}$ Department of Physical Medicine and Rehabilitation, Virginia Commonwealth University, Richmond, VA; ${ }^{3}$ Hunter \\ Holmes McGuire VA Medical Center (VAMC), Richmond, VA; ${ }^{4}$ Center for Chronic Disease Outcomes Research, Min- \\ neapolis VA Health Care System, Minneapolis, MN; ${ }^{5}$ Department of Medicine, University of Minnesota, Minneapolis, \\ MN; ${ }^{6}$ Defense and Veterans Brain Injury Center, Richmond, VA; ${ }^{7}$ Rehabilitation and Prosthetics Services, Lebanon \\ VAMC, Lebanon, PA; ${ }^{8}$ Department of Psychiatry, University of Minnesota, Minneapolis, MN; ${ }^{9}$ Department of Physical \\ Medicine and Rehabilitation, Washington VAMC, Washington, DC; and Department of Physical Medicine and Reha- \\ bilitation, Georgetown University Medical Center, Washington, DC
}

\begin{abstract}
To identify the prevalence of traumatic brain injury (TBI), posttraumatic stress disorder (PTSD), and pain in Veterans from Operation Iraqi Freedom/Operation Enduring Freedom/Operation New Dawn (OIF/OEF/OND), Veterans who received any inpatient or outpatient care from Veterans Health Administration (VHA) facilities from 2009 to 2011 were studied. A subset of Veterans was identified who were diagnosed with TBI, PTSD, and/or pain (head, neck, or back) as determined by their International Classification of Diseases-9th Revision-Clinical Modification codes. Between fiscal years 2009 and 2011, 613,391 Veterans accessed VHA services at least once (age: $31.9+/-9.6 \mathrm{yr}$ ). TBI diagnosis in any 1 year was slightly less than $7 \%$. When data from 3 years were pooled, $9.6 \%$ were diagnosed with TBI, 29.3\% were diagnosed with PTSD, and $40.2 \%$ were diagnosed with pain. The full polytrauma triad expression (TBI, PTSD, and pain) was diagnosed in $6.0 \%$. Results show that increasing numbers of Veterans from OIF/ OEF/OND accessed VHA over a 3 year period. Among those with a TBI diagnosis, the majority also had a mental health disorder, with approximately half having both PTSD and pain. While the absolute number of Veterans increased by over $40 \%$ from 2009 to 2011, the proportion of Veterans diagnosed with TBI and the high rate of comorbid PTSD and pain in this population remained relatively stable.
\end{abstract}

Key words: military healthcare, military Veterans, Operation Enduring Freedom, Operation Iraqi Freedom, Operation New Dawn, pain, posttraumatic stress disorder, PTSD, TBI, traumatic brain injury.

\footnotetext{
Abbreviations: $\mathrm{FY}=$ fiscal year, ICD-9-CM = International Classification of Diseases-9th Revision-Clinical Modification, NPCD $=$ National Patient Care Database, OEF $=$ Operation Enduring Freedom, OIF = Operation Iraqi Freedom, OND = Operation New Dawn, PTBRI = Polytrauma Blast-Related Injury, PTSD = posttraumatic stress disorder, QUERI = Quality Enhancement Research Initiative, $\mathrm{SM}=$ servicemember, $\mathrm{TBI}=$ traumatic brain injury, VA = Department of Veterans Affairs, $\mathrm{VHA}=$ Veterans Health Administration.

*Address all correspondence to David X. Cifu, MD; Department of Physical Medicine and Rehabilitation, 1223 East Marshall St, Richmond, VA 23298-0677; 804-8284231; fax: 804-828-6755. Email: dcifu@vcu.edu http://dx.doi.org/10.1682/JRRD.2013.01.0006
} 


\section{INTRODUCTION}

Traumatic brain injury (TBI) has been termed the "signature injury" of the wars in Iraq and Afghanistan [1], but posttraumatic stress disorder (PTSD) and pain are also commonly reported in this patient cohort. The more defining condition associated with these wars, however, is better captured by the term "polytrauma," which describes two or more injuries to organ systems or parts of the body that create potentially life-threatening injuries and/or disruption to physical, mental, and psychological functioning [2]. That is, servicemembers (SMs) and Veterans returning from these wars with TBI more often than not also have other war-related medical problems.

Prior studies have identified TBI, PTSD, and pain to be the major comorbid elements most frequently seen in those previously deployed to Iraq and Afghanistan who return with polytrauma [3-4]. This constellation of comorbidities has been referred to as the "polytrauma triad." Investigators have noted that among SMs treated at an inpatient polytrauma rehabilitation unit within the Department of Veterans Affairs (VA), 80 to 93 percent were diagnosed with TBI, 81 to 96 percent with pain, and 44.0 to 52.6 percent with a mental health disorder $[3,5]$. Those with deployment-related difficulties from Operation Enduring Freedom (OEF), Operation Iraqi Freedom (OIF), and Operation New Dawn (OND) receiving care in VA outpatient polytrauma programs were diagnosed with three or more postconcussive (TBI) symptoms 67 to 97 percent of the time, complained of persistent pain issues 82 to 97 percent of the time, and were diagnosed with PTSD 68 to 71 percent of the time [4,6]. The Appendix (available online only) outlines the official locales and durations of these conflicts. A number of other potentially disabling concomitant conditions can also accompany the initial TBI exposure and add to the complexity of diagnosis and management, including substance abuse, depression, and generalized anxiety disorder [6].

A 2009 national sample of all OIF/OEF Veterans who received VA care during that year revealed that 6.7 percent had been diagnosed with TBI [7]. In this TBI group, 89 percent had a concomitant mental health disorder, with the most frequent diagnosis being PTSD (73\%); 70 percent had a concomitant pain disorder; and 54 percent had both PTSD and pain (the polytrauma triad). These data are of great importance in providing a "snapshot" of polytrauma nationally. However, they reflect only 1 year of the VA's experience, and a broader, multi- year evaluation is needed to better understand the phenomenon. Other investigators have looked at longer time spans, but these studies have focused on relatively small, local cohorts [3-4]. The present study represents the first examination of a large, national sample over a multiyear time frame. To this end, the Polytrauma Blast-Related Injury (PTBRI) Quality Enhancement Research Initiative's (QUERI's) ongoing VA systemwide, longitudinal tracking data of OIF/OEF/OND Veterans with TBI sequelae and other coexisting conditions were queried and the findings were analyzed [8-10].

\section{METHODS}

The study population consisted of all Veterans who received any inpatient or outpatient care from Veterans Health Administration (VHA) facilities in fiscal years (FYs) (October to September) 2009, 2010, or 2011. VA policy requires that all OIF/OEF/OND Veterans who seek initial service of any kind in the VA be screened for deployment-related TBI (as well as PTSD), and those who report trauma exposure with altered consciousness, peritraumatic sequelae (e.g., dizziness, headache, ongoing confusion), and ongoing neurobehavioral symptoms be referred for a comprehensive TBI evaluation. Within this cohort, a subset of Veterans who were diagnosed with TBI; PTSD; and/or common head, neck, or back pain, as determined by their International Classification of Diseases-9th Revision-Clinical Modification (ICD-9CM) [11] codes, was identified (see Table 1 for specific ICD-9-CM coding associated with each diagnosis). As in any healthcare setting, Veterans were assigned ICD-9$\mathrm{CM}$ codes by their clinicians at the time of their inpatient or outpatient care episodes. The specific diagnoses of TBI, PTSD, or pain were made at any point in their medical care received at a VA facility, not necessarily in a specialty clinic. Data from the VA FY2009-11 National Patient Care Database (NPCD) patient treatment files and outpatient care files were used to identify patients in the cohort diagnosed with the conditions of interest for this research, including TBI, PTSD, and/or pain.

Descriptive statistics were used to report the mean incidence of the diagnoses of TBI, PTSD, and pain (head, neck, or back), both in isolation and in combination. Percentages were computed. All analyses were performed using SAS version 9.2 (SAS Institute Inc; Cary, North Carolina). 
Table 1.

Polytrauma diagnoses and associated International Classification of Diseases-9th Revision-Clinical Modification (ICD-9-CM) codes.

\begin{tabular}{lc}
\hline \multicolumn{1}{c}{ Diagnosis } & ICD-9-CM Code \\
\hline Traumatic Brain Injury & $310.2,800.0-801.9,803.0-804.9,850.0-854.1,905.0,907.0,950.1-950.3,959.01,959.9, \mathrm{~V} 15.52$ \\
Posttraumatic Stress Disorder & 309.81 \\
Pain & $721.3 \mathrm{x}-721.9 \mathrm{x}, 722.2 \mathrm{x}, 722.30,722.70,722.80,722.90,722.32,722.72,722.82,722.92,722.33$, \\
$\quad$ Back & $722.73,722.83,722.93,724 . x x, 737.1,737.3,738.4,738.5,739.2,739.3,739.4,756.10,756.11$, \\
& $756.12,756.13,756.19,805.4,805.8,839.2,839.42,846,846.0,847.1,847.3,847.2,847.9$ \\
$\quad$ Neck & $721.0 \mathrm{x}, 721.1 \mathrm{x}, 722.0 \mathrm{x}, 722.31,722.71,722.81,722.91,723 . x x, 839.0,839.1,847.0$ \\
Headache/Migraine & $346 . x, 307.81,784.0,339 . x x$ \\
\hline \hline
\end{tabular}

\section{RESULTS}

For FY2009-11, 613,391 unique OIF/OEF/OND Veterans accessed VHA inpatient or outpatient services at least once. Table 2 describes demographic characteristics. Overall, the Veterans were $31.9 \pm 9.6 \mathrm{yr}$ old (mean \pm standard deviation). Of the Veterans, 51.8 percent had at least one of the three polytrauma diagnoses (TBI, PTSD, or pain) during the triennium.

While the incidence of a TBI diagnosis in any one year's data was slightly less than 7 percent, when data from 3 years were pooled, 9.6 percent or 58,885 unique OIF/OEF/OND Veterans were diagnosed with TBI in at least one of those years. This apparent disparity between individual and cumulative years relates to the fact that 1 year of data measures any diagnosis assigned during that FY, while the cumulative prevalence takes into account all visits over the 3-year period. Similarly, when pooling all 3 years, 29.3 percent or 179,723 Veterans were diagnosed with PTSD and 40.2 percent or 246,883 Veterans were diagnosed with head, neck, or back pain. The incidence of the full polytrauma triad expression of TBI, PTSD, and pain was diagnosed in 6.0 percent $(36,800)$ of all Veterans. These increases reflect the variability of the services provided to each OIF/OEF/OND Veteran during any given year and the accompanying diagnoses for those services. The presence of these diagnoses could not be associated with the etiology or timing of the causative event(s) or combat-relatedness. Of note, only 0.8 percent of all $613,391 \mathrm{OIF} / \mathrm{OEF} / \mathrm{OND}$ Veterans received a diagnosis of isolated TBI (i.e., unaccompanied by either pain or PTSD). Other combinations of these diagnoses may be found in Table $\mathbf{3}$ and Figures $\mathbf{1}$ and $\mathbf{2}$.

Since many Veterans access care on an ongoing basis, oftentimes over multiple FYs, the total number of OIF/ $\mathrm{OEF} / \mathrm{OND}$ Veterans receiving care for these 3 years was higher $(n=613,391)$ than the number of unique Veterans
Table 2.

Population demographics of all Operation Iraqi Freedom/Operation Enduring Freedom/Operation New Dawn Veterans seen from FY2009 to FY2011 $(N=613,391)$.

\begin{tabular}{cc}
\hline Demographic & $\boldsymbol{n}(\%)$ or Mean \pm SD \\
\hline Age $^{*}(y r)$ & $31.9 \pm 9.6$
\end{tabular}

Sex

Female $\quad 73,863(12)$

Male $\quad 537,453(88)$

Race

White $353,110(58)$

Nonwhite $\quad 122,531(20)$

Unknown 137,750 (22)

Ethnicity

Hispanic $\quad 58,801$ (10)

Non-Hispanic $\quad 436,440(71)$

Unknown $\quad 118,150$ (19)

Urban/Rural $^{\dagger}$

Urban $\quad 356,317(58)$

Rural 227,743 (37)

Highly Rural $\quad 5,886$ (1)

Unknown 23,445 (4)

Service-Connected Disability

None

$281,384(46)$

$0 \% \quad 20,641(3)$

$10 \%-40 \% \quad 159,649(26)$

$50 \%-90 \% \quad 134,880(22)$

$100 \% \quad 16,837$ (3)

${ }^{*}$ Calculated as each Veteran's age on first day of FY2009.

†Urban: $\geq 1,000$ people per square mile. Rural: Any non-urban or non-highly rural area. Highly rural: $<7$ people per square mile.

$\mathrm{FY}=$ fiscal year, $\mathrm{SD}=$ standard deviation.

who accessed care over any of the 3 years of the analyses $(\mathrm{FY} 2009=327,388, \mathrm{FY} 2010=398,453$, and FY2011 $=$ 471,383). The number of Veterans accessing services increased by 122 percent from FY2009 to FY2010 and 118 percent from FY2010 to FY2011, with the total increase over the triennium being 144 percent. The relative 
Table 3.

Proportion (in percentage) of Operation Iraqi Freedom/Operation Enduring Freedom/Operation New Dawn Veterans with diagnoses of traumatic brain injury (TBI); pain of head, neck, or back; and/or posttraumatic stress disorder (PTSD).

\begin{tabular}{|c|c|c|c|c|}
\hline Diagnosis & $\begin{array}{c}\text { FY2009 } \\
(n=327,388)\end{array}$ & $\begin{array}{c}\text { FY2010 } \\
(n=\mathbf{3 9 8}, 453)\end{array}$ & $\begin{array}{c}\text { FY2011 } \\
(n=471,383)\end{array}$ & $\begin{array}{c}\text { FY2009-FY2011 } \\
(n=613,391)\end{array}$ \\
\hline No TBI, Pain, or PTSD & 52.4 & 52.0 & 52.0 & 48.2 \\
\hline Pain Only & 18.1 & 18.3 & 18.0 & 20.1 \\
\hline PTSD Only & 12.1 & 12.1 & 12.4 & 9.5 \\
\hline Pain and PTSD & 10.7 & 10.9 & 11.1 & 12.6 \\
\hline TBI Only & 0.7 & 0.7 & 0.7 & 0.8 \\
\hline TBI and Pain & 1.1 & 1.1 & 1.1 & 1.6 \\
\hline TBI and PTSD & 1.2 & 1.2 & 1.1 & 1.3 \\
\hline TBI, Pain, and PTSD & 3.7 & 3.8 & 3.5 & 6.0 \\
\hline \multicolumn{5}{|l|}{ Any Diagnoses } \\
\hline TBI & 6.7 & 6.8 & 6.5 & 9.6 \\
\hline Pain & 33.6 & 34.1 & 33.7 & 40.2 \\
\hline PTSD & 27.6 & 27.9 & 28.2 & 29.3 \\
\hline
\end{tabular}

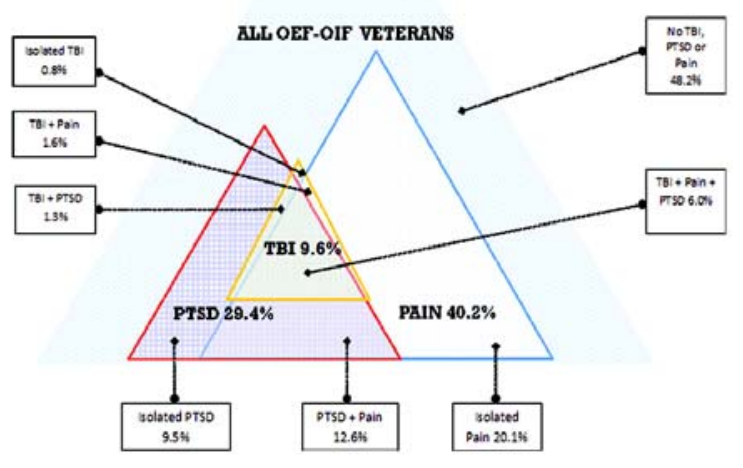

Figure 1.

Three-year prevalence of traumatic brain injury (TBI), posttraumatic stress disorder (PTSD), and/or pain diagnoses in Operation Iraqi Freedom (OIF)/Operation Enduring Freedom (OEF) Veterans (fiscal years 2009-2011).

proportions of Veterans with the polytrauma triad did not change meaningfully across any or all of the years.

\section{DISCUSSION}

This nationwide, multiyear investigation is notable in three aspects. First, the data are strikingly consistent from

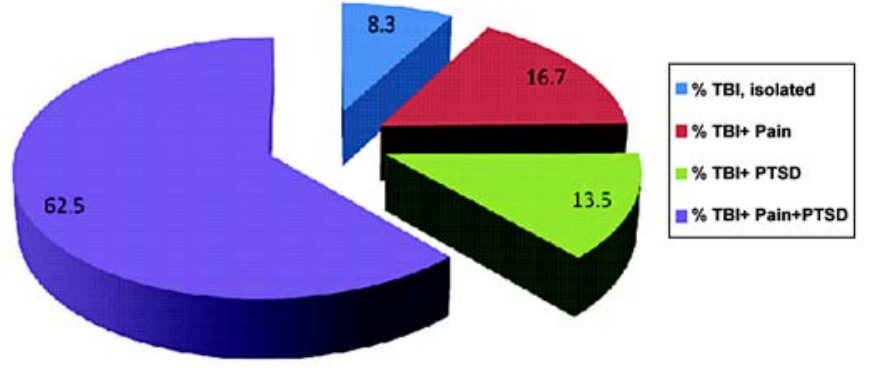

Figure 2.

Comorbidities of Operation Iraqi Freedom/Operation Enduring Freedom/Operation New Dawn Veterans with traumatic brain injury (TBI). PTSD = posttraumatic stress disorder.

year to year in all diagnostic categories and dyad and triad combinations. Second, the prevalence of TBI is lower than previously reported, in particular for the diagnosis of isolated TBI (Figure 2). Third, among those Veterans with clinician-diagnosed TBI, we find that mental health, particularly PTSD, and pain-related comorbidity is the norm. Both the individual year and pooled 3-year prevalence of all diagnoses are considerably smaller than estimates that have been reported in either self-report survey or single-center (TBI) studies $[4,12]$. Of note, the survey work was based on self-report of the Veteran's or SM's recollection of the injury and related symptoms as 
measured by in-person written or telephone surveys and were not exclusive to VA-enrolled Veterans [13-15]. This carries an inherent risk of false positives and false negatives, as well as sampling differences [16]. The gold standard for TBI diagnosis is a clinical interview and evaluation with a specialist (as opposed to self-report surveys, imaging, or laboratory testing) because of the difficulty obtaining accurate information on TBI history through brief self-report measures and no defined physiologic or biologic marker [7]. Self-report measures may overestimate the rate of TBI compared with clinical assessment, just as they have been found to overestimate the rate of PTSD relative to gold standard interviews [1718]. On the other hand, clinical assessment is also subject to error, and in fact, these medical diagnoses may be underreported in VA records [18-19]. Those individuals who have had an OIF/OEF/OND deployment-related TBI, but who had no acute or persistent sequelae, should still be recorded as having a diagnosis of TBI but on rare occasions may not receive a referral for specialty TBI care, or more typically, even if referred, patients may elect to not follow up with the specialist. The VA is currently reporting that about 95 percent of these Veterans are successfully screened and that about 75 percent of those who screen positive undergo comprehensive evaluation [20]. While it is most likely that the diagnosis of TBI is appropriately entered into the NPCD system for those individuals with persistent symptoms who are referred and/or seen by the specialty programs for care, it is unclear whether those individuals who have sustained a TBI but have had complete resolution of symptoms are consistently recorded for this exposure in the system. In sum, while our findings describe the proportion of OIF/OEF/OND Veteran VA users with TBI diagnosis in the VA FY200911 administrative data, they may not describe the actual incidence of TBI or the impairment or disability related to $\mathrm{TBI}$ in the population of all OIF/OEF/OND Veterans.

The findings presented in this report should be taken in context with potential limitations. First, we did not examine the universe of possible TBI-related comorbidities but rather focused on mental health and select painrelated problems in order to better characterize the prevalence of the polytrauma triad in VA users with TBI. Indeed, the difficulties inherent to postdeployment syndrome extend beyond the polytrauma triad to include these other conditions [21]. Second, the findings are based on administrative data, which may be limited by errors in documentation of the patient characteristics, diagnoses, or procedures. Details on the severity of the TBI are difficult to reliably obtain from the administrative record, so while the majority of Veterans with a diagnosis of TBI are likely to have mild TBI, we were not able to report results separately based on the severity of the injury. Additionally, we did not have available information on diagnoses of OIF/OEF/OND Veterans who did not use VA services. As one would expect across the 3 years of this study, the overall assessment and care of OIF/OEF/OND Veterans with TBI, PTSD, and/or pain have experienced an ongoing process of service enhancements under the guidance of the VHA's Polytrauma System of Care. These improvements in service have included educational initiatives, clinical training, and translational research that have informed both specialty and primary care clinicians. While these developments are likely to have improved the overall awareness and diagnostic precision for the entire polytrauma triad, this may not be as easily reflected in the data analyzed. While changes in combat injury patterns may have been present and increased the incidence of the TBI-pain dyad, it is also feasible that the increased emphasis on pain awareness and education had an effect. Of note, while this investigation used more than 50 ICD-9-CM codes for pain diagnoses, numerous other pain codes were not included. In contrast, the longstanding and pervasive emphasis in the VA system regarding PTSD and other mental health disorders [20,22-23] appears to have already sensitized VA providers to the diagnosis of PTSD in patients with TBI.

The challenges of using ICD-9-CM codes to characterize prevalence of various health conditions across large healthcare systems are formidable and may have contributed to inaccuracies in this investigation. As Lorence has noted, imprecise coding has become more of a factor because physicians are asked to make coding decisions directly into electronic records and may code differently than coding specialists [24]. Lorence also noted considerable regional variations in coding practices that have important implications for national studies and need to be considered carefully [24]. Others have noted problems with coding of injury causation [25], as well as issues involved with inconsistent PTSD diagnosis and coding [26]. The present study did not attempt to control for TBI causation or time of injury. This limitation may add "noise" to the results, and future investigations are needed to address this effectively. While standardized training and certification programs are currently in place 
for medical coding, the accuracy of coding would be further enhanced by formalizing diagnostic criteria. This could be accomplished using normative, standardized instruments with proven reliability, such as the ClinicianAdministered PTSD Scale [27] or the Visual Analog Scale for Pain [28]. Others have more bluntly stated that "Relying on medical records staff to code cases using [ICD-9-CM] numbers without providing some direction as to an appropriate code is a major part of the problem" and called for an overarching primary TBI diagnosis with more detailed coding added if warranted [29]. The possibility that the VA's emphasis on educating providers about TBI may have resulted in heightened use of TBI codes, even though the bulk of symptoms could be accounted for with a mental health diagnosis, has also been raised [30]. The difficulty in coding is also magnified because TBI, most particularly mild TBI, is a historical diagnosis not even requiring the presence of current symptoms.

\section{CONCLUSIONS}

This investigation represents the first multiyear, systemwide analysis of TBI, mental health, and pain-related comorbidities and triad diagnostic trends from the VHA. The findings support that large and increasing numbers of Veterans from the OIF/OEF/OND wars accessed the VHA for healthcare over a 3-year period. Of those Veterans, approximately 10 percent were diagnosed with TBI, 30 percent with PTSD, and 40 percent with pain, and approximately 6 percent had all three diagnoses or the polytrauma triad. Among those with a TBI diagnosis, the majority had a clinician-diagnosed mental health disorder and approximately half of those with TBI had both PTSD and pain. Overall, while the absolute number of OIF/OEF/OND Veterans increased by over 40 percent between FY2009 and FY2011, the relative proportion of Veterans diagnosed with TBI and the high rate of comorbid PTSD and pain in this population remained relatively stable.

\section{ACKNOWLEDGMENTS}

\section{Author Contributions:}

Study concept and design: D. X. Cifu, B. C. Taylor, W. F. Carne. Acquisition of data: B. C. Taylor, N. A. Sayer, E. H. Campbell. Analysis and interpretation of data: D. X. Cifu, B. C. Taylor, W. F. Carne, D. Bidelspach, N. A. Sayer, J. Scholten, E. H. Campbell.
Drafting of manuscript: D. X. Cifu, B. C. Taylor, W. F. Carne, D. Bidelspach, N. A. Sayer, J. Scholten, E. H. Campbell. Critical revision of manuscript for important intellectual content: D. X. Cifu, B. C. Taylor, W. F. Carne, N. A. Sayer.

Statistical analysis: B. C. Taylor, W. F. Carne, N. A. Sayer. Obtained funding: B. C. Taylor, N. A. Sayer.

Administrative, technical, or material support: N. A. Sayer, D. X. Cifu.

Study supervision: N. A. Sayer, D. X. Cifu.

Financial Disclosures: The authors have declared that no competing interests exist.

Funding/Support: This material was based on work supported by the VA Office of Research and Development Health Services Research and Development Service (grant PLY 05-2010-2) from the PTBRI QUERI and the Defense and Veterans Brain Injury Center. The funding source had no role in the study design, analysis, interpretation of the data, writing of the manuscript, or decision to submit the article for publication.

Institutional Review: The institutional review board of the Minneapolis VA Health Care System approved the study, including a Health Insurance Portability and Accountability Act waiver of authorization. Disclaimer: The views expressed herein do not necessarily represent the views of the VA or the U.S. Government.

\section{REFERENCES}

1. Independent Review Group on Rehabilitative Care and Administrative Processes at Walter Reed Army Medical Center and National Naval Medical Center. Rebuilding the trust: Report on rehabilitative care and administrative processes at Walter Reed Army Medical Center and National Naval Medical Center. Alexandria (VA): Independent Review Group; 2007.

2. Department of Veterans Affairs. VHA Handbook 1172.1: Polytrauma system of care. Washington (DC): Veterans Health Administration; 2013 Mar 20.

3. Clark ME, Bair MJ, Buckenmaier CC 3rd, Gironda RJ, Walker RL. Pain and combat injuries in soldiers returning from Operations Enduring Freedom and Iraqi Freedom: Implications for research and practice. J Rehabil Res Dev. 2007;44(2):179-94. [PMID:17551872] http://dx.doi.org/10.1682/JRRD.2006.05.0057

4. Lew HL, Otis JD, Tun C, Kerns RD, Clark ME, Cifu DX. Prevalence of chronic pain, posttraumatic stress disorder, and persistent postconcussive symptoms in OIF/OEF veterans: Polytrauma clinical triad. J Rehabil Res Dev. 2009; 46(6):697-702. [PMID:20104399] http://dx.doi.org/10.1682/JRRD.2009.01.0006

5. Sayer NA, Cifu DX, McNamee S, Chiros CE, Sigford BJ, Scott S, Lew HL. Rehabilitation needs of combat-injured service members admitted to the VA Polytrauma Rehabilitation Centers: The role of PM\&R in the care of wounded 
warriors. PM R. 2009;1(1):23-28. [PMID:19627869]

http://dx.doi.org/10.1016/j.pmrj.2008.10.003

6. Lew HL, Poole JH, Vanderploeg RD, Goodrich GL, Dekelboum S, Guillory SB, Sigford B, Cifu DX. Program development and defining characteristics of returning military in a VA Polytrauma Network Site. J Rehabil Res Dev. 2007; 44(7):1027-34. [PMID:18075959]

http://dx.doi.org/10.1682/JRRD.2007.05.0073

7. Taylor BC, Hagel EM, Carlson KF, Cifu DX, Cutting A, Bidelspach DE, Sayer NA. Prevalence and costs of cooccurring traumatic brain injury with and without psychiatric disturbance and pain among Afghanistan and Iraq War Veteran V.A. users. Med Care. 2012;50(4):342-46. [PMID:22228249] http://dx.doi.org/10.1097/MLR.0b013e318245a558

8. QUERI Polytrauma/Blast-Related Injuries [Internet]. Fiscal year 2009 VA utilization report for OEF/OIF veterans diagnosed with TBI. Minneapolis (MN): Minneapolis VA Health Care System; 2011 Oct [cited 2012 Dec 25]. Available from: http://www.queri.research.va.gov/ptbri/docs/ FY09-TBI-Diagnosis-HCU-Report.pdf

9. QUERI Polytrauma/Blast-Related Injuries [Internet]. Fiscal year 2010 VA utilization report for Iraq and Afghanistan war veterans diagnosed with TBI. Minneapolis (MN): Minneapolis VA Health Care System; 2012 May [cited 2012 Dec 25]. Available from: http://www.queri.research.va.gov/ ptbri/docs/FY10-TBI-Diagnosis-HCU-Report.pdf

10. QUERI Polytrauma/Blast-Related Injuries [Internet]. Fiscal year 2011 VA utilization report for Iraq and Afghanistan war veterans diagnosed with TBI. Minneapolis (MN): Minneapolis VA Health Care System; 2012 Sep [cited 2012 Dec 25]. Available from: http://www.queri.research.va.gov/ ptbri/docs/FY11-TBI-Diagnosis-HCU-Report.pdf

11. U.S. Health Care Financing Administration, U.S. National Center for Health Statistics. ICD. 9. CM: International classification of diseases, 9th revision, clinical modification. 6th ed. Washington (DC): U.S. Department of Health and Human Services, Public Health Service, Health Care Financing Administration; 2006.

12. McCrea M, Pliskin N, Barth J, Cox D, Fink J, French L, Hammeke T, Hess D, Hopewell A, Orme D, Powell M, Ruff R, Schrock B, Terryberry-Spohr L, Vanderploeg R, Yoash-Gantz R. Official position of the military TBI task force on the role of neuropsychology and rehabilitation psychology in the evaluation, management, and research of military veterans with traumatic brain injury. Clin Neuropsychol. 2008;22(1):10-26. [PMID:18247218] http://dx.doi.org/10.1080/13854040701760981

13. MacGregor AJ, Shaffer RA, Dougherty AL, Galarneau MR, Raman R, Baker DG, Lindsay SP, Golomb BA, Corson KS. Prevalence and psychological correlates of traumatic brain injury in Operation Iraqi Freedom. J Head
Trauma Rehabil. 2010;25(1):1-8. [PMID:20051901]

http://dx.doi.org/10.1097/HTR.0b013e3181c2993d

14. Bray RM, Pemberton MR, Hourani LL, Witt M, Olmsted KL. Department of Defense survey of health related behaviors among active duty military personnel. Ft. Belvoir (VA): Defense Technical Information Center; 2009.

15. Hoge CW, Goldberg HM, Castro CA. Care of war veterans with mild traumatic brain injury-flawed perspectives. N Engl J Med. 2009;360(16):1588-91. [PMID:19369664] http://dx.doi.org/10.1056/NEJMp0810606

16. Iverson GL, Langlois JA, McCrea MA, Kelly JP. Challenges associated with post-deployment screening for mild traumatic brain injury in military personnel. Clin Neuropsychol. 2009;23(8):1299-1314. [PMID:19882473] http://dx.doi.org/10.1080/13854040903153902

17. Richardson LK, Frueh BC, Acierno R. Prevalence estimates of combat-related post-traumatic stress disorder: Critical review. Aust N Z J Psychiatry. 2010;44(1):4-19. [PMID:20073563] http://dx.doi.org/10.3109/00048670903393597

18. Roemer L, Litz BT, Orsillo SM, Ehlich PJ, Friedman MJ. Increases in retrospective accounts of war-zone exposure over time: The role of PTSD symptom severity. J Trauma Stress. 1998;11(3):597-605. [PMID:9690197] http://dx.doi.org/10.1023/A:1024469116047

19. Hill JJ 3rd, Mobo BH Jr, Cullen MR. Separating deploymentrelated traumatic brain injury and posttraumatic stress disorder in veterans: Preliminary findings from the Veterans Affairs traumatic brain injury screening program. Am J Phys Med Rehabil. 2009;88(8):605-14. [PMID:19620825] http://dx.doi.org/10.1097/PHM.0b013e3181ae0f83

20. Reeves RR, Parker JD, Konkle-Parker DJ. War-related mental health problems of today's veterans: New clinical awareness. J Psychosoc Nurs Ment Health Serv. 2005; 43(7):18-28. [PMID:16116923]

21. Cifu DX, Blake PC. Overcoming post-deployment syndrome: A six-step mission to health. New York (NY): Demos Health; 2011.

22. Friedman MJ. Veterans' mental health in the wake of war. N Engl J Med. 2005;352(13):1287-90. [PMID:15800223] http://dx.doi.org/10.1056/NEJMp058028

23. Rosen CS, Chow HC, Finney JF, Greenbaum MA, Moos RH, Sheikh JI, Yesavage JA. VA practice patterns and practice guidelines for treating posttraumatic stress disorder. J Trauma Stress. 2004;17(3):213-22. [PMID:15253093] http://dx.doi.org/10.1023/B:JOTS.0000029264.23878.53

24. Lorence D. Regional variation in medical classification agreement: Benchmarking the coding gap. J Med Syst. 2003;27(5):435-43. [PMID:14584620] http://dx.doi.org/10.1023/A:1025607805588

25. Carlson KF, Nugent SM, Grill J, Sayer NA. Accuracy of external cause-of-injury coding in VA polytrauma patient 
discharge records. J Rehabil Res Dev. 2010;47(8):689-97. [PMID:21110244]

26. Gravely AA, Cutting A, Nugent S, Grill J, Carlson K, Spoont M. Validity of PTSD diagnoses in VA administrative data: Comparison of VA administrative PTSD diagnoses to self-reported PTSD Checklist scores. J Rehabil Res Dev. 2011;48(1):21-30. [PMID:21328160] http://dx.doi.org/10.1682/JRRD.2009.08.0116

27. Blake DD, Weathers FW, Nagy LM, Kaloupek DG, Gusman FD, Charney DS, Keane TM. The development of a clinician-administered PTSD scale. J Trauma Stress. 1995;8(1):75-90. [PMID:7712061] http://dx.doi.org/10.1002/jts.2490080106

28. Todd KH. Pain assessment instruments for use in the emergency department. Emerg Med Clin North Am. 2005; 23(2):285-95. [PMID:15829383]

http://dx.doi.org/10.1016/j.emc.2004.12.002

29. McNaughton H, Wadsworth K. Assessing the accuracy of hospital admission and discharge diagnosis of traumatic brain injury in a New Zealand hospital. N Z Med J. 2000; 113(1110):184-86. [PMID:10917079]

30. Vasterling JJ, Verfaellie M, Sullivan KD. Mild traumatic brain injury and posttraumatic stress disorder in returning veterans: Perspectives from cognitive neuroscience. Clin Psychol Rev. 2009;29(8):674-84. [PMID:19744760]

http://dx.doi.org/10.1016/j.cpr.2009.08.004

Submitted for publication January 12, 2013. Accepted in revised form March 15, 2013.

This article and any supplementary material should be cited as follows:

Cifu DX, Taylor BC, Carne WF, Bidelspach D, Sayer NA, Scholten J, Campbell EH. Traumatic brain injury, posttraumatic stress disorder, and pain diagnoses in OIF/ OEF/OND Veterans. J Rehabil Res Dev. 2013;50(9): 1169-76.

http://dx.doi.org/10.1682/JRRD.2013.01.0006

ResearcherID/ORCID: Brent C. Taylor, PhD: A-8069-2009

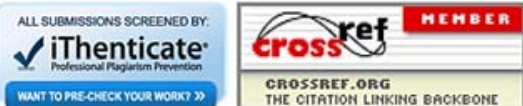

